\title{
Preparation of Manganese Oxide/Graphene Aerogel and Its Application as an Advanced Supercapacitor Electrode Material
}

\author{
Xia Qiu ${ }^{1}$, Danyan $\mathrm{Xu}^{1}$,Ling $\mathrm{Ma}^{2}$ and Yong Wang, ${ }^{3, *}$ \\ ${ }^{1}$ College of Electrical and Electronic Information Engineering, Hubei Polytechnic University, \\ Huangshi, 435000, P.R.China \\ ${ }^{2}$ College of Information Science and Engineering, Wuchang Shouyi University, Wuhan, 430000, \\ P.R.China \\ ${ }^{3}$ HuangShi Central Hospital, Edong Healthcare, Huangshi, 435000, P.R.China \\ *E-mail: yongwang_hpu@qq.com
}

doi: $10.20964 / 2017.03 .07$

Received: 18 November 2016 / Accepted: 29 December 2016 / Published: 12 February 2017

Electrochemical supercapacitors (ECs) with high energy density and power capability have demonstrated promising potential in various energy applications. In this study, $3 \mathrm{D} \mathrm{MnO}_{2} / \mathrm{rGO}$ aerogels with excellent electrical conductivity was successfully prepared with a simple hydrothermal method. The as-prepared 3D aerogels could be applied for constructing the electrode of supercapacitor directly without the demand of other additives. Asymmetric supercapacitors were then constructed with $\mathrm{Na}_{2} \mathrm{SO}_{4}$ aqueous solution as electrolyte, $\mathrm{MnO}_{2} / \mathrm{rGO}$ aerogel and $\mathrm{rGO}$ aerogel as positive and negative electrode, respectively. The asymmetric supercapacitor demonstrated maximum energy density of 18.2 $\mathrm{Wh} / \mathrm{kg}$ with power density of $400 \mathrm{~W} / \mathrm{kg}$ and excellent cycle stability as well.

Keywords: Supercapacitor; Aerogel; Graphene; Manganese oxide; Hydrothermal

\section{$\underline{\text { FULL TEXT }}$}

(C) 2017 The Authors. Published by ESG (www.electrochemsci.org). This article is an open access article distributed under the terms and conditions of the Creative Commons Attribution license (http://creativecommons.org/licenses/by/4.0/). 